\title{
Comparison of the stress-strain state reinforced concrete structures (columns and trusses) with linear and nonlinear statements of the deformation law
}

\author{
Irina Polyakova ${ }^{*}$ and Raykhan Imambayeva \\ Kazakh Head Architecture and Civil Engineering Academy, 050043, Almaty, Kazakhstan
}

\begin{abstract}
The article discusses the calculations of some structures under various laws of deformation. Four laws are adopted: linear, nonlinear exponential, nonlinear with a falling branch, taking into account the creep of concrete, and nonlinear according to the experimental data. As a result of the calculation, the results are given for various efforts, comparative characteristics are given, and conclusions are drawn about the operation of structures and the work of materials. The following has been conducted: 1 . Calculation of structures according to the $1^{\text {st }}$ law of nonlinear deformation of materials - exponential law of deformation $[1,2,3]$. 2. Calculation of structures according to the $2^{\text {nd }}$ law - the law of nonlinear deformation of concrete with a falling branch (according to Eurocode 2) [4, 5]. 3. Calculation of structures according to the $3^{\text {rd }}$ law of nonlinear deformation of materials - the exponential law of deformation of the second type $[1,2$, $3]$.
\end{abstract}

\section{Introduction}

In the modern construction industry, there are very few objects, the physical properties of which could be described by the linear laws of deformation. Basically, a significant part of concrete and reinforcement properties can be described by nonlinear formulas for the deformations' dependence on stresses.

Structural calculations based on linear relationships between stresses and displacements (due to a non-deformable design model and Hooke's law) are now considered as approximate, although the experienced specialists will use this method of calculating a structure with the smallest errors for a long time.

On the other hand, the construction of buildings and structures that are unique in size is due to the lack of analogues, as a result of which it requires a deep computational analysis, which can take into account the specific factors of the structures operation during the entire life cycle. One of the most important characteristics of a structure behavior is the physical nonlinearity that occurs during loading, between stresses and deformations. This nonlinearity complicates the algorithm; therefore, many modern construction calculations are carried out in the elastic stage, which leads to overestimated results that do not correspond to the real work of the structure. In this regard, it is necessary to develop such

\footnotetext{
*Corresponding author:Pim8192@mail.ru
} 
models of structures that sufficiently fully and unambiguously confirm the objects under study and the processes of their deformation.

Calculation according to the nonlinear law makes it possible to observe significant effects of the structure operation, such as redistribution of forces from more loaded elements to the less loaded ones, an increase in displacements in time due to the rheological properties of the material (creep, etc.). The form of the concrete state diagram for the nonlinear structural calculations is shown in Figure 1.

The load-bearing structural elements in the considered design scheme are columns and trusses, which in general represent a frame. The dimensions of the building on the plan are $24 \mathrm{~m} * 48 \mathrm{~m}$. The height of the columns is $9.6 \mathrm{~m}$. The total height is $12 \mathrm{~m}$. The length of the truss is $24 \mathrm{~m}$. The pitch of the columns is $6 \mathrm{~m}$. The main type of section is a beam, which is used for all elements.

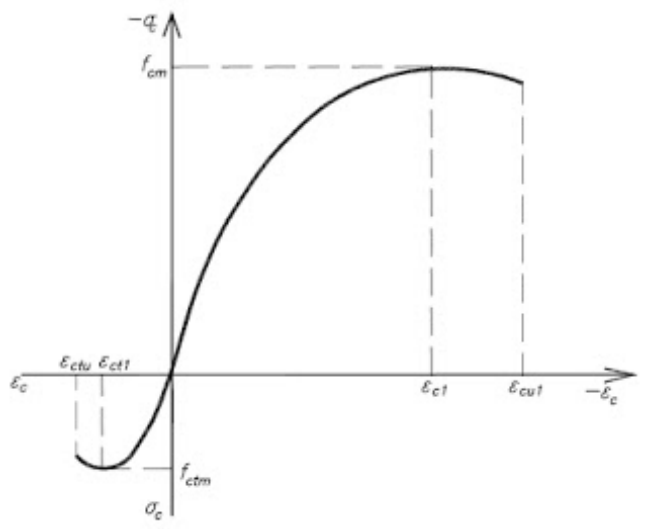

Fig. 1. Concrete state diagram for nonlinear structural analysis

The sections of the truss elements are rectangular $15 \times 15 \mathrm{~cm}$, the columns are $40 \times 40 \mathrm{~cm}$. The entire structure is under the influence of its own weight and external loads. The design scheme is shown in Figure 2.

The first calculation was performed with a linear setting of the target, i.e., the classical Hooke's law of stress-strain dependence is fulfilled: $\sigma=E \varepsilon$. The calculated percentage of reinforcement for the columns and trusses is shown in Figures 3 and 4.

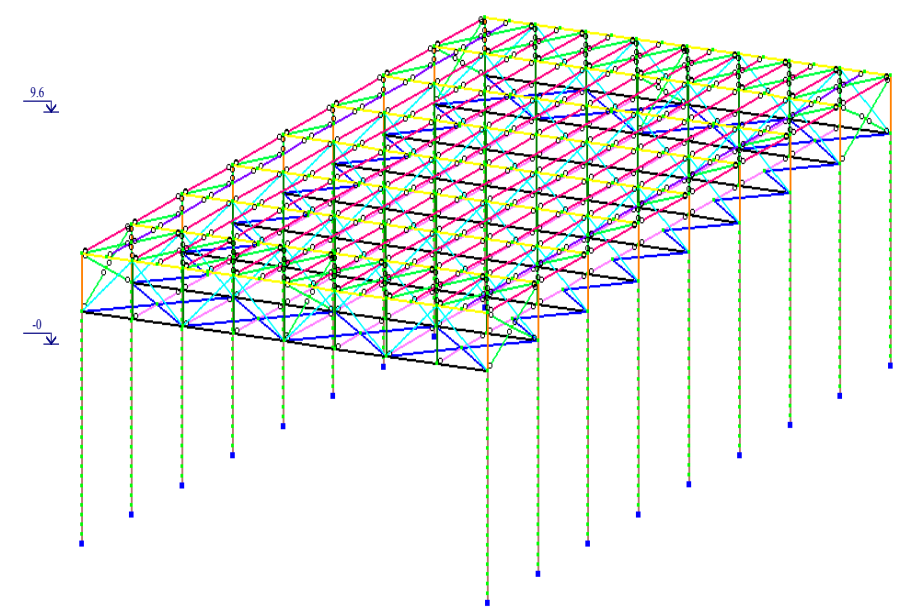

Fig. 2. General scheme 


\section{Linear calculation:}

\section{Nonlinear Law 1 - Exponential Strain Law:}

For any exponentially growing quantity, the fact that the greater the value of the argument (relative deformation), the faster the function (stress) grows, is important. But at the same time, unlike the hyperbolic one, the exponential curve never goes to infinity for a finite period of time.

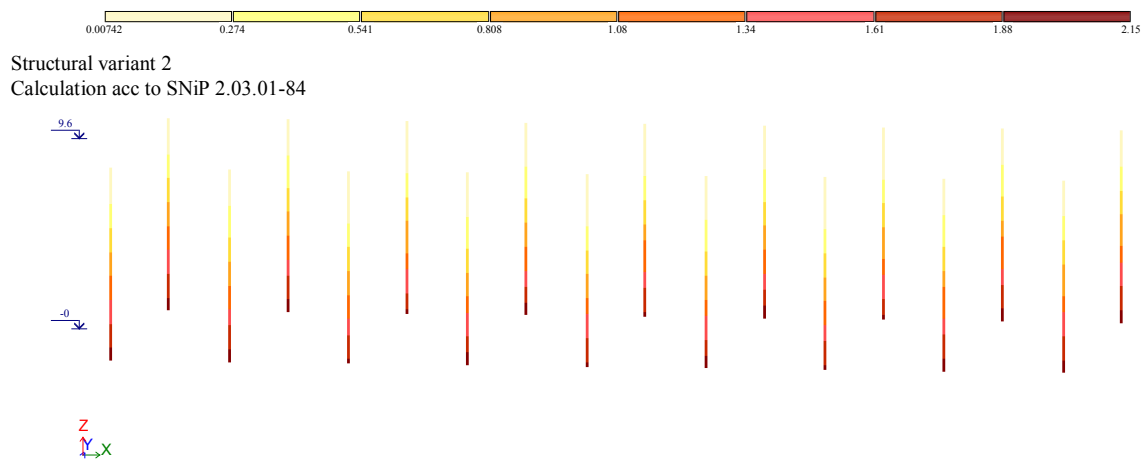

Fig. 3. Percentage of reinforcement (Area of full reinforcement) Symmetrical reinforcement. Maximum 2.14 per item 17.

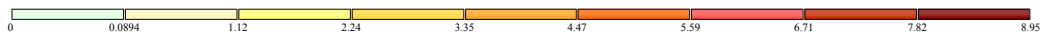

Structural variant 2

Calculation acc to SNiP 2.03.01-84

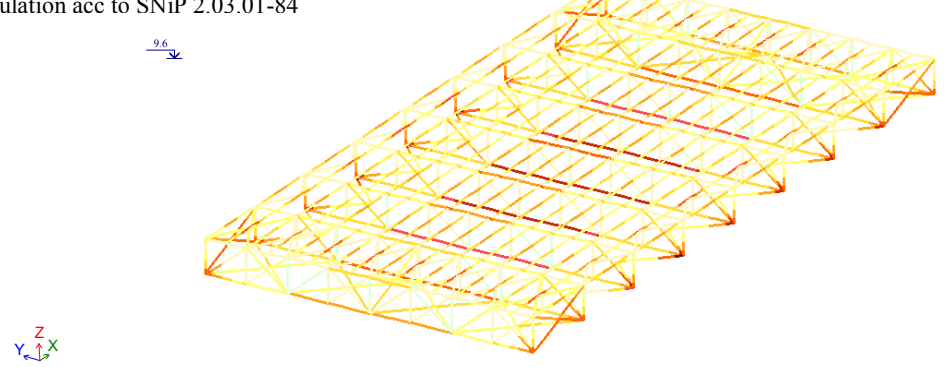

Fig. 4. Percentage of reinforcement (Total area of reinforcement) Asymmetrical reinforcement. Maximum 8.04 per item 726.

As a result, exponential growth turns out to be faster than any power growth and, moreover, any linear growth (refer with fig. 5).

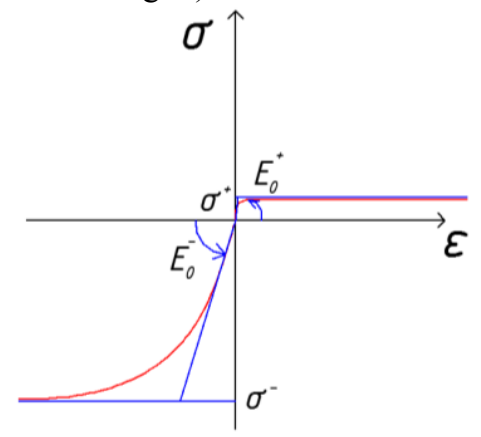

Fig. 5. The $1^{\text {st }}$ law schedule nonlinear deformation of the base material 
Table 1. Parameters of the $1^{\text {st }}$ law of the base material nonlinear deformation

\begin{tabular}{|c|c|c|}
\hline Designation & Value & Unit \\
\hline $\begin{array}{c}\mathrm{E}_{0}^{-} \text {the initial value of Young's modulus for } \\
\text { compression }\end{array}$ & 3000000 & $\mathrm{t} / \mathrm{m}^{2}$ \\
\hline $\mathrm{E}_{0}^{+}$initial value of Young's modulus in tension & 3000000 & $\mathrm{t} / \mathrm{m}^{2}$ \\
\hline$\sigma^{-}$compressive stress limit & -1479 & $\mathrm{t} / \mathrm{m}^{2}$ \\
\hline$\sigma^{+}$tensile stress limit & 107.1 & $\mathrm{t} / \mathrm{m}^{2}$ \\
\hline$\varepsilon^{-}$ & -0.025 & \\
\hline$\varepsilon^{+}$ & 0.025 & \\
\hline
\end{tabular}

\section{Non-linear law 2 - non-linear concrete deformation law:}

The second law of nonlinearity is the law of concrete nonlinear deformation with a falling branch. This law is taken into account in the normative documents of Eurocode 2 (refer with fig. 6,7,8).

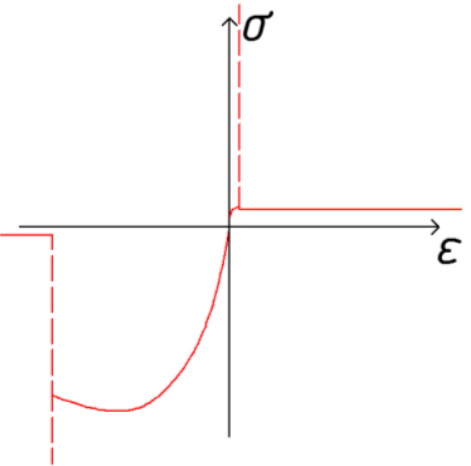

Fig. 6. Schedule of the $2^{\text {nd }}$ law of nonlinear deformation for basic material

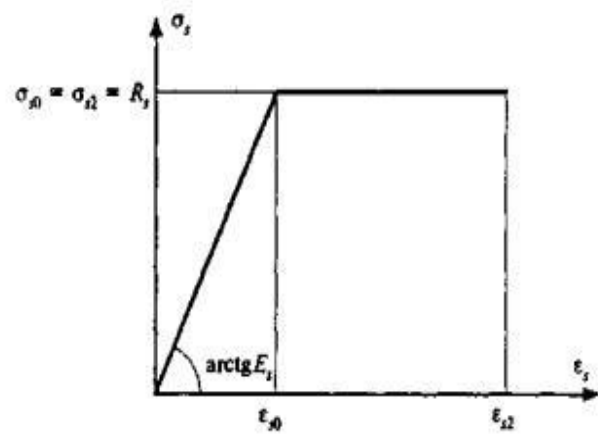

Fig. 7. Status diagram tensile reinforcement $\varepsilon_{i}$ - deformation at the $i$-th intermediate point; $\sigma$ - voltage at the $i$-th intermediate point.

Table 2. Parameters of the 2 nd law of nonlinear deformation of the basic material

\begin{tabular}{|c|c|c|}
\hline Designation & Value & Unit \\
\hline $\begin{array}{l}\mathrm{E}_{\mathrm{cm}}(-) \text { initial modulus of elasticity in compression, } \\
\text { secant modulus of concrete elasticity; }\end{array}$ & 3000000 & $\mathrm{t} / \mathrm{m}^{2}$ \\
\hline $\mathrm{E}_{\mathrm{ctm}}(+)$ initial tensile modulus; & 3000000 & $\mathrm{t} / \mathrm{m}^{2}$ \\
\hline $\begin{array}{l}f_{\mathrm{cm}}(-) \text { ultimate compressive stress (negative value), } \\
\text { average axial tensile strength of concrete; }\end{array}$ & -1479 & $\mathrm{t} / \mathrm{m}^{2}$ \\
\hline $\begin{array}{l}\mathrm{f}_{\mathrm{ctm}}(+) \text { ultimate tensile stress, average value of } \\
\text { concrete compressive strength; }\end{array}$ & 107.1 & $\mathrm{t} / \mathrm{m}^{2}$ \\
\hline $\begin{array}{l}\varepsilon_{\mathrm{cu}}(-) \text { ultimate relative deformation of concrete in } \\
\text { compression }\end{array}$ & -0.0048 & \\
\hline$\left.\varepsilon_{\mathrm{c}(}-\right)$ relative deformation of concrete in compression & -0.0028 & \\
\hline$\varepsilon_{\mathrm{ctu}}(+)$ ultimate relative tensile deformation of concrete & -0.00022 & \\
\hline
\end{tabular}

Since the second law can be applied only to concrete, for the reinforcing material the piecewise linear law of deformation will be chosen (refer with fig. 7). 


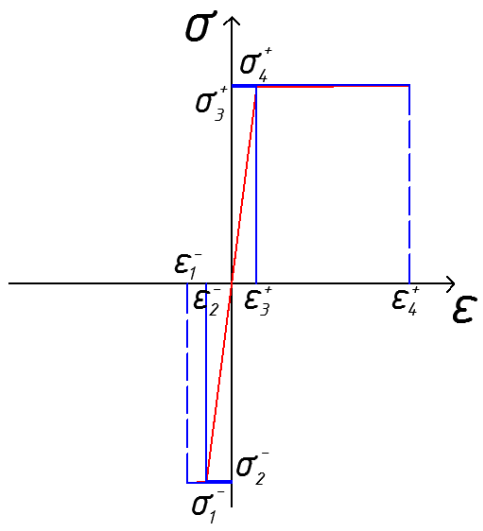

Fig. 8. Schedule of the 2nd law of nonlinear deformation for reinforcing material

"Lira-CAD-2020" considers the problem in stresses, not deformations, it will be necessary to set a horizontal section of the diagram with a certain drop. All required values in the diagram are characteristic. The given loads will be the same.

Compression branch characteristics are negative numbers. The regions are set from left to right (compression - stretching). The number of $i$-points is not limited. If the value of the generalized deformation goes beyond the specified polyline, then the shutdown of the material is simulated $\left(\mathrm{E}_{\mathrm{i}}=1\right)$ elementary site from the section operation. It is forbidden to set horizontal sections.

The law with index 2 can be applied to any material, both basic and reinforcing.

Reinforcement properties are set for the reinforcing material. The set properties of A500C reinforcement are as follows.

Table 3. Parameters of the 2 nd law of nonlinear deformation for the reinforcing material

\begin{tabular}{|c|c|c|c|}
\hline Designation & Deformation & Designation & Voltage \\
\hline$\varepsilon_{1}^{-}$ & -0.00346 & $\sigma_{1}^{-}$ & $-50001 \mathrm{t} / \mathrm{m}^{2}$ \\
\hline$\varepsilon_{2}^{-}$ & -0.00238 & $\sigma_{2}^{-}$ & $-50000 \mathrm{t} / \mathrm{m}^{2}$ \\
\hline$\varepsilon_{3}^{+}$ & 0.00238 & $\sigma_{3}^{+}$ & $50000 \mathrm{t} / \mathrm{m}^{2}$ \\
\hline$\varepsilon_{4}^{+}$ & 0.0222 & $\sigma_{4}^{+}$ & $50001 \mathrm{t} / \mathrm{m}^{2}$ \\
\hline
\end{tabular}

Nonlinear law 3 - exponential law of deformation for reinforced concrete (Fig. 9.10):

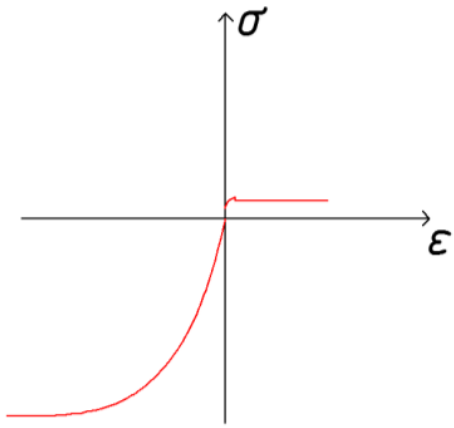

Fig. 9. Schedule of the 3rd law of nonlinear deformation for the basic material 
Table 4. Parameters of the 3rd law of nonlinear deformation of the basic material

\begin{tabular}{|c|c|c|}
\hline $\begin{array}{c}\text { Designation } \\
\mathrm{E}_{0}^{-} \text {the initial value of Young's modulus for } \\
\text { compression }\end{array}$ & 3000000 & Unit \\
\hline $\mathrm{E}_{0}^{+}$initial value of Young's modulus in tension & 3000000 & $\mathrm{t} / \mathrm{m}^{2}$ \\
\hline$\sigma^{-}$compressive stress limit & -1479 & $\mathrm{t} / \mathrm{m}^{2}$ \\
\hline$\sigma^{+}$tensile stress limit & 107.1 & $\mathrm{t} / \mathrm{m}^{2}$ \\
\hline$\varepsilon^{-}$ultimate compressive strain & -0.0048 & \\
\hline$\varepsilon^{+}$ultimate tensile strain & 0.0031 & \\
\hline
\end{tabular}

The properties of the steel are set for the reinforcing material. The A500 brand reinforcement will be chosen for this structure.

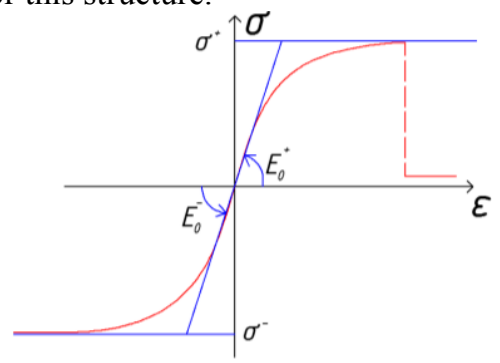

Fig. 10. Schedule of the 3rd law of nonlinear deformation for the reinforcing material

Table 5. Parameters of the $3^{\text {rd }}$ law of nonlinear deformation for reinforcing material

\begin{tabular}{|c|c|c|}
\hline Designation & Value & Unit \\
\hline $\mathrm{E}_{0}^{-}$ & 21000000 & $\mathrm{t} / \mathrm{m}^{2}$ \\
\hline $\mathrm{E}_{0}^{+}$ & 21000000 & $\mathrm{t} / \mathrm{m}^{2}$ \\
\hline$\sigma^{-}$ & -28500 & $\mathrm{t} / \mathrm{m}^{2}$ \\
\hline$\sigma^{+}$ & 28500 & $\mathrm{t} / \mathrm{m}^{2}$ \\
\hline$\varepsilon^{-}$ & -0.025 & \\
\hline$\varepsilon^{+}$ & 0.025 & \\
\hline
\end{tabular}

\section{Calculation and calculation results according to the linear law}

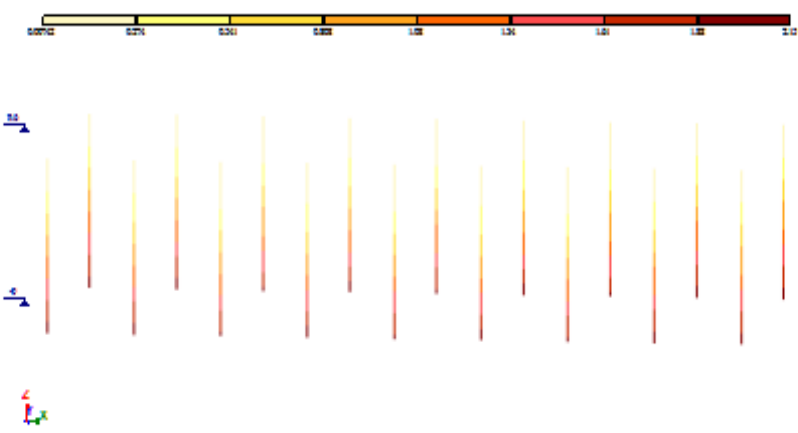

Fig. 11. Reinforcement percentage (Area of full reinforcement) Symmetrical reinforcement. Maximum 2.14 per item 17. 


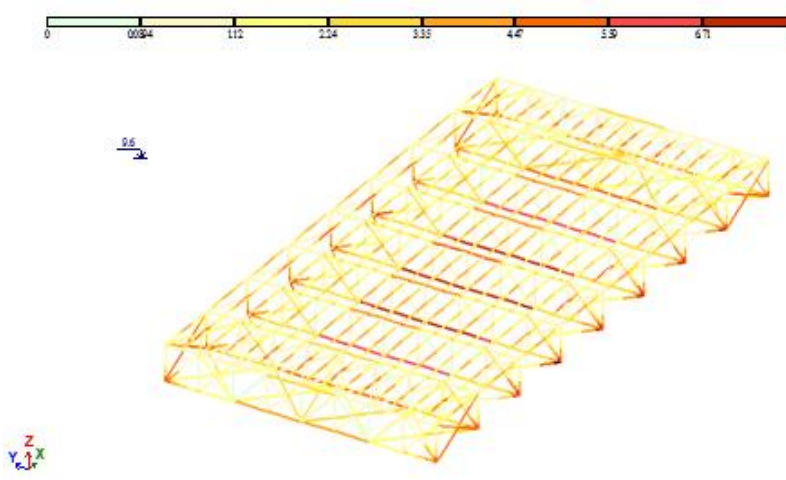

Fig. 12. Reinforcement percentage (Total area of reinforcement) Asymmetrical reinforcement. Maximum 8.94 per item 726 .

\section{Calculation and calculation results according to nonlinear law 1}

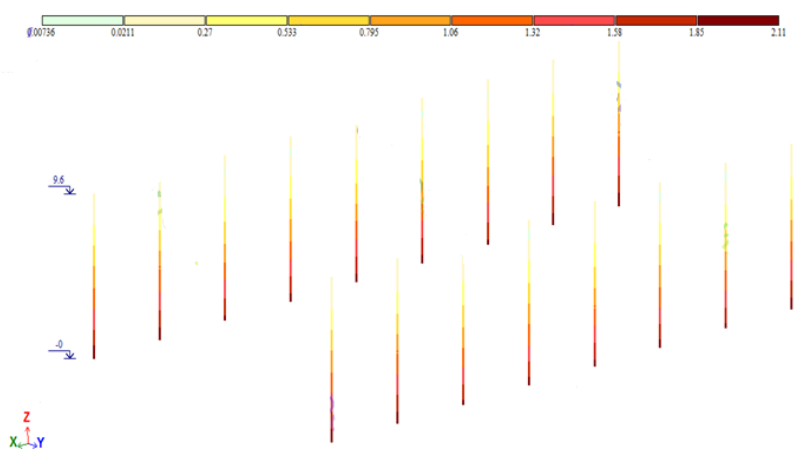

Fig. 13. Reinforcement percentage (Area of full reinforcement) Symmetrical reinforcement. Maximum 2.11 per item 1.

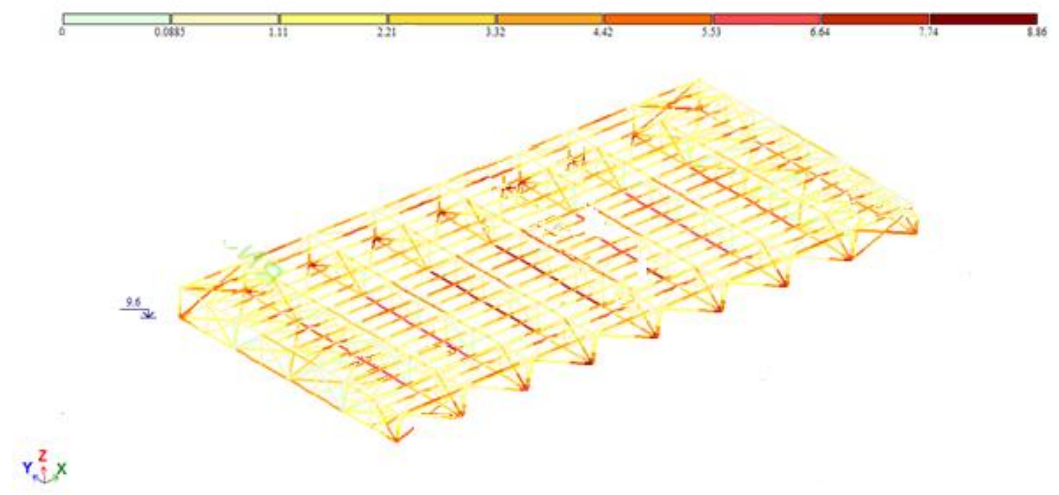

Fig. 14. Reinforcement percentage (Area of full reinforcement) Unsymmetrical reinforcement. Maximum 8.85 per item 741 . 


\section{Calculation and calculation results according to nonlinear law} 2

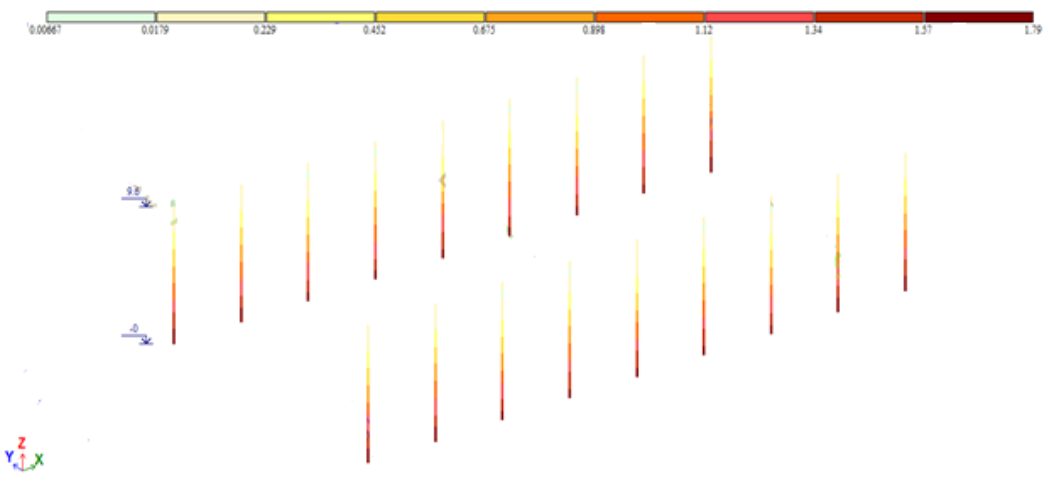

Fig. 15. Reinforcement percentage (Area of full reinforcement) Symmetrical reinforcement. Maximum 1.79 per item 21 .

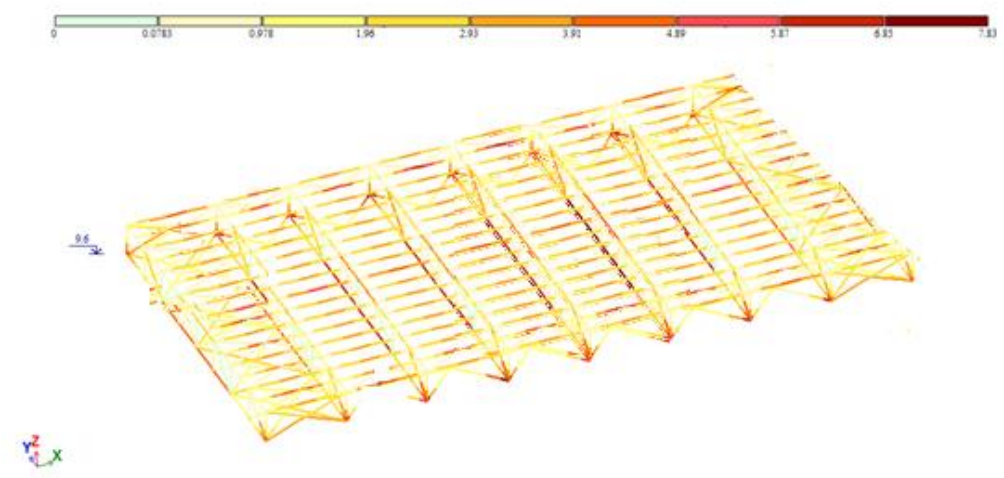

Fig. 16. Reinforcement percentage (Total area of reinforcement) Asymmetrical reinforcement. Maximum 7.83 per item 726 .

\section{Calculation and calculation results according to nonlinear law 3}

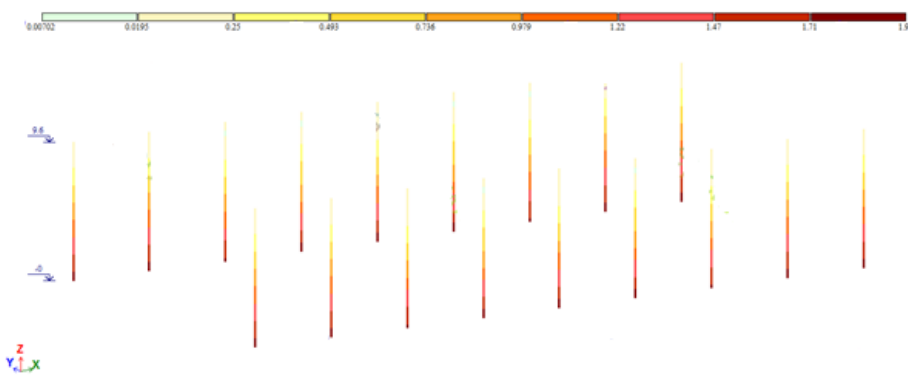

Fig. 17. Reinforcement percentage (Area of full reinforcement) Symmetrical reinforcement. Maximum 1.95 per item 41. 


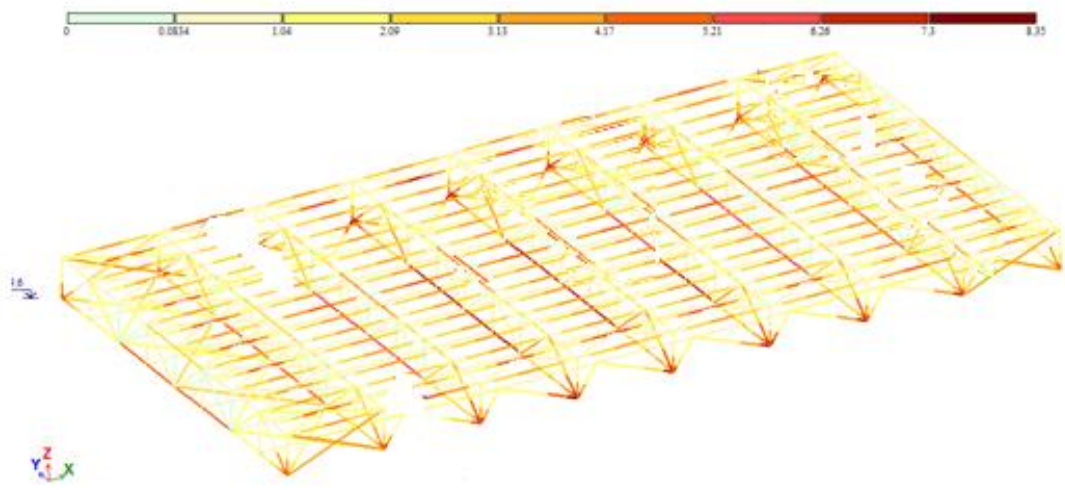

Fig. 18. Reinforcement percentage (Total area of reinforcement) Asymmetrical reinforcement. Maximum 8.34 per item 728 .

\section{Comparison of linear and non-linear calculation results}

Table 7. Comparison of maximum forces in columns of a regular scheme

\begin{tabular}{|l|c|c|c|c|c|c|}
\hline Name & $\mathrm{N}(\mathrm{t})$ & $\mathrm{Mk}\left(\mathrm{t}^{*} \mathrm{~m}\right)$ & $\mathrm{My}\left(\mathrm{t}^{*} \mathrm{~m}\right)$ & $\mathrm{Qz}(\mathrm{t})$ & $\mathrm{Mz}\left(\mathrm{t}^{*} \mathrm{~m}\right)$ & $\mathrm{Qy}(\mathrm{t})$ \\
\hline \multirow{2}{*}{$\begin{array}{l}\text { Linear } \\
\text { Law }\end{array}$} & 25 & 13 & 1050 & 37 & 1094 & 1094 \\
\cline { 2 - 7 } & -30.1976 & -0.52445 & -41.9733 & - & -45.9332 & -5.79291 \\
\hline $\begin{array}{l}\text { Non- } \\
\text { linear }\end{array}$ & 25 & 13 & 1050 & 37 & 1094 & 1094 \\
\cline { 2 - 7 } 1st law & 30.159428 & 0.519627 & 41.562099 & 4.825614 & 45.512711 & 5.741879 \\
\hline $\begin{array}{l}\text { Non- } \\
\text { linear } \\
\text { 2nd } \\
\text { law }\end{array}$ & 25 & 13 & 1050 & 37 & 1094 & 1094 \\
\cline { 2 - 7 } $\begin{array}{l}\text { Non- } \\
\text { linear } \\
\text { 3rd } \\
\text { law }\end{array}$ & - & - & - & - & - & - \\
\cline { 2 - 7 } & 29.738405 & 0.468472 & 37.199303 & 4.321081 & 41.052036 & 5.201032 \\
\hline
\end{tabular}

Table 8. Comparison of the maximum longitudinal forces in trusses of the regular scheme

\begin{tabular}{|c|c|c|}
\hline \multirow[t]{2}{*}{$\mathrm{N}(\mathrm{t})$ Linear } & 225 item & 58.883492 \\
\hline & 116 item & -64.6987 \\
\hline \multirow{2}{*}{$\begin{array}{c}\mathrm{N}(\mathrm{t}) \text { Non-linear 1st } \\
\text { law }\end{array}$} & 225 & 58.772823 \\
\hline & 116 & -64.577087 \\
\hline \multirow{2}{*}{$\begin{array}{l}\mathrm{N}(\mathrm{t}) \text { Non-linear 2nd } \\
\text { law }\end{array}$} & 225 & 57.552986 \\
\hline & 116 & -63.236427 \\
\hline \multirow{2}{*}{$\begin{array}{l}\mathrm{N}(\mathrm{t}) \text { Non-linear 3rd } \\
\text { law }\end{array}$} & 225 & 58.189224 \\
\hline & 116 & -63.935684 \\
\hline
\end{tabular}

Table 9. Comparison of the maximum percent of reinforcement of the regular scheme

\begin{tabular}{|c|c|c|}
\hline Name & columns \% & truss \% \\
\hline Linear & 2.14 & 8.94 \\
\hline Non-linear 1st law & 2.11 & 8.86 \\
\hline Non-linear 2nd law & 1.79 & 7.83 \\
\hline
\end{tabular}




\begin{tabular}{|c|c|c|}
\hline Non-linear 3rd law & 1.95 & 8.34 \\
\hline
\end{tabular}

\section{Conclusion}

Calculation of the structures using various (linear and nonlinear) laws of deformation makes it possible to draw the following conclusions:

1. The difference in the forces in the columns with respect to the longitudinal force $(N)$ in the direction of increase with a linear law of deformation is $0.13,1.52,0.79 \%$, respectively.

2. Difference in shear forces in columns $\left(Q_{z}\right)$ upward with a linear law of deformation is $0.99,12.78,6.39 \%$, respectively.

3. Difference in shear forces in columns $\left(Q_{y}\right)$ upward with a linear law of deformation is $0.89,11.38,5.73 \%$, respectively.

3. Difference in bending moment forces in columns $\left(M_{x}\right)$ upward with a linear law of deformation is $0.93,11.95,6 \%$, respectively.

4. Difference in bending moment forces in columns $\left(M_{y}\right)$ upward with a linear law of deformation is $0.99,12.83,6.42 \%$, respectively.

5. Difference in forces in the columns in terms of torque $\left(M_{z}\right)$ upward with a linear law of deformation is $0.91,0.92,11.89 \%$, respectively.

6. The difference in the forces in the tensile elements of the truss in terms of the longitudinal force $(N)$ in the direction of increase with a linear law of deformation is 0.19 , $2.31,1.19 \%$, respectively.

7. The difference in the forces in the compressed elements of the truss in terms of the longitudinal force $(N)$ in the direction of increase with a linear law of deformation is 0.19 , $2.31,1.19 \%$, respectively.

8. The difference in the percentage of column structures reinforcement in the direction of increasing with a linear law is $1.42,19.55,9.74 \%$, respectively.

9. The difference in the percentage of truss structures reinforcement in the direction of increasing with a linear law is $0.9,14.18,7.19 \%$, respectively.

In general, it can be concluded that with a linear law of deformation in the design of structures using the LIRA SAPR -2020 program, all structures are calculated with a built-in safety margin. This is a positive result. As for the economy of materials, here is a different picture: when applying the linear law of deformation, there is a certain over expenditure of materials.

\section{References}

1. BC KR 1.01-104-2014. Construction terminology. Building construction. Building materials and products.

2. BC KR EN 1990:2002+A1:2005/2011. Structural Design Fundamentals.

3. BC KR EN 1998-1:2004/2012. Design of earthquake-resistant structures.

4. BC KR 2.04-01-2017. Building climatology.

5. SNiP KR 5.03-34-2005. Concrete and reinforced concrete structures. Basic Provisions. 